\title{
Reference to Abstract Entities within Clausal Complements
}

\author{
MICHAEL HEGARTY \\ Louisiana State University
}

\section{Introduction}

This paper will use techniques from the literature on referring forms to investigate reference to abstract entities within clausal complements in factive, interrogative, and bridge verb contexts. We'll see that abstract entities introduced within factive complements exhibit identical possibilities for subsequent pronominal reference to those introduced within interrogative complements, and different from those introduced within bridge verb complements. This will motivate parallel semantic representations of factive and interrogative complementation. The investigation of reference to abstract entities will be extended to new types of abstract entities, and the nature of abstract entities denoted by nominal and non-nominal expressions will be discussed.

The issue to be investigated is whether abstract entities, upon being introduced into a discourse, are accessible to immediate subsequent reference with a personal pronoun or a demonstrative pronoun. This question can be formulated within standard theories of referential accessibility, including Accessibility Theory (Ariel 1990), Centering Theory (Grosz, Joshi and Weinstein 1983, 1995; and others) and the Givenness Hierarchy (Gundel, Hedberg and Zacharski 1993).

Centering Theory makes predictions pertaining to entities introduced or evoked within an utterance $U_{i}$ in discourse $D$ regarding their status in the next utterance, $U_{i+1}$. The entities introduced or evoked within utterance $U_{i}$ in $D$ are the forward looking centers of $U_{i}$ in $D, \operatorname{cf}\left(U_{i}, D\right)$. The predictions made by Centering Theory include which among the forward looking centers of $U_{i}$ is likely to be a backward looking center of $U_{i+1}$ in $D, \operatorname{cb}\left(U_{i+1}, D\right)$, corresponding roughly to the topic of $U_{i+1}$. Within Centering Theory, the question pursued here is whether an abstract entity introduced in an utterance $U_{i}$ is a backward looking center of utterance $\mathrm{U}_{\mathrm{i}+1}$.

Accessibility Theory ranks nominal forms according to the degree of accessibility they indicate of their referents for the hearer, as assumed by the speaker. Unstressed pronouns, proximal demonstratives, and distal 
demonstratives are distinct points on an extensive, many-point scale for degree of accessibility indicated.

The Givenness Hierarchy associates nominal forms, in a one-to-many fashion, with linearly ordered cognitive statuses. The minimal status possible for each form is shown in (1).

(1) in-focus $>$ activated $>$ familiar $>$ uniquely $>$ referential $>$ type identifiable identifiable

$\begin{array}{lllll}\text { pronouns } & \begin{array}{l}\text { this } \mathrm{N} \\ \text { this }\end{array} & \text { that } \mathrm{N} \text { the } \mathrm{N} \quad \begin{array}{l}\text { this } \mathrm{N} \\ \text { (indef) }\end{array} & a \mathrm{~N}\end{array}$

that

With respect to the Givenness Hierarchy, the question to be investigated here is whether an abstract entity, upon being introduced in an utterance $U_{i}$ in discourse $\mathrm{D}$, can be assumed (by the speaker) to have the cognitive status in-focus (for the hearer), or merely the status activated, at the onset of utterance $U_{i+1}$ in D. We will frame referential accessibility results in terms of the Givenness Hierarchy here, but return in section 5 to implications for Centering Theory, concerning the ranking of forward looking centers.

In (2) below, a referent is given the status in-focus by utterance of the first sentence, and is then referred to by a personal pronoun in the second. In (3), a referent which is introduced more peripherally in the first sentence is made activated, but not in-focus, by the first sentence, and can be referred to more felicitously by a demonstrative than a personal pronoun in the second. ${ }^{1}$

(2) a. My neighbors's bull mastiff bit a girl on a bike. [GHZ 1993; (9)] It's the same dog that bit Mary Ben last summer.

b. Sam found an abandoned dog. It had a broken leg.

(3) Sears delivered new siding to my new neighbors with the bull mastiff. [GHZ 1993; (10)]

\# It's the same dog that bit Mary Ben last summer.

That's the same dog that bit Mary Ben last summer.

\section{Review of results on the referential accessibility of abstract entities}

Abstract entities (including propositions, properties, facts and situations, introduced by non-nominal expressions) have somewhat restricted possibilities for pronominal reference. As noted in the literature (Webber 1988, Gundel, Hedberg and Zacharski 1989), propositions, facts and situations introduced by a clause can

\footnotetext{
${ }^{1}$ In Centering Theory, the dog in (2), but not in (3), is the preferred center of the first utterance, and the backward looking center of the second utterance.
} 


\section{Reference to Abstract Entities}

be referred to by personal pronouns and by demonstrative pronouns, but not always with equal felicity.

Borthen, Fretheim and Gundel $(1997,1999)$ point out that, in $(4 a)$, the personal pronoun it most naturally refers to the snake, not to the fact or situation of the snake being on the desk. In (4b), the demonstrative pronoun that can refer to the fact or situation that there is a snake on the desk, and given this reference to the fact or situation, the subsequent personal pronoun it can then felicitously refer to this fact or situation.

(4) a. There was a snake on my desk. It scared me. [(4a,b) from BFG 1997]

b. There was a snake on my desk. That scared me, and it scared my office mate too.

Borthen, Fretheim and Gundel $(1997,1999)$ draw the generalization that an abstract entity introduced by a higher-order expression is, at that mention, activated, but not in-focus, and is therefore available to subsequent reference with a demonstrative pronoun, but not a personal pronoun; an additional mention is required for such an entity to become in-focus, and therefore available to reference with a personal pronoun.

The referent of a bridge verb complement exhibits the same behavior, as discussed by Gundel, Hedberg and Zacharski (1993). In (5), when (5a) is used to introduce the proposition that the company destroyed the file, my consultants found that this proposition can be more felicitously referred to by that in $(5 \mathrm{c})$, than by it in (5b). However, when (5c) is followed by (5d), the further mention of the proposition within $(5 \mathrm{c})$ makes it accessible to reference by it in (5d).

(5) a. Alex believes that the company destroyed the file.

b. It's false; the file has been submitted to the district judge.

c. That's false; the file has been submitted to the district judge.

d. And if it were true, the company's case would not be in better shape. [it/that $=$ that the company destroyed the file $]$

Furthermore, these effects are observed for properties introduced within bridge verb complements. In (6), my consultants found that the property "being fluent in Berber" introduced within the clausal complement can be more felicitously referred to by that in (6b) than by it in (6a).

(6) a. Alex believes that this candidate is fluent in Berber. It's the most important qualification for this position.

b. Alex believes that this candidate is fluent in Berber. That's the most important qualification for this position. 
There are two important caveats to these observations: First, the preference for that over it in (5) only holds when the proposition is newly introduced in (5a). When this proposition is an established discourse entity, the preference for that does not hold. (We all believe that the company destroyed the file. It's not even controversial around here.) See Borthen, Fretheim and Gundel (1999) for discussion of the role of extralinguistic context in promoting the salience of an abstract entity. Second, these effects are dependent on the nature of the linguistic expression used to introduce the entity in question; contrast the examples in (4)(5) with those in (7).

(7) a. At that moment, Maria brought up another fact (- - that there is a snake in my desk). It sent shivers down my spine. [it = the fact]

b. Alex then introduced a new proposition (- that the company actually destroyed the file.) But it was immediately pooh-poohed. [it $=$ the proposition]

c. Another proposition then occurred to me (-that the company actually destroyed the file). But I immediately dismissed it. [it = the proposition]

In (7), the pronoun it can refer to the fact or the proposition after one mention. ${ }^{2}$ But these examples introduce the fact or proposition with a nominal expression. Crucially, the nominal is indefinite, so the introduced entity is new to the discourse.

\section{Referential accessibility of abstract entities mentioned within factive and interrogative complements}

With factive complements, given the presupposed status of the content of the complement clause, we might expect immediate subsequent reference with a pronominal form to be possible. Indeed, in (8) and (9), my consultants found it and that to be equally capable of referring to the content of the complements of the factive verbs regret and verify; in fact, they exhibited a slight preference for it over that.

(8) a. Alex regrets that the company destroyed the file; it has impeded the investigation.

b. Alex regrets that the company destroyed the file; that has impeded the investigation.

[it/that $=$ that the company destroyed the file $]$

\footnotetext{
${ }^{2}$ With the parenthetical material in (7), the subsequent pronoun may count, not as a second mention of the abstract entity, but as a third mention. See Borthen, Fretheim and Gundel (1999) for discussion of this issue. The point here is that, even without the parenthetical material, when the pronoun is clearly only a second mention, the abstract entity is accessible to reference with this pronoun, in contrast to the pattern in (4)-(5).
} 
(9) A: Alex verified that the company destroyed the file.

B: It was obvious to everyone in my office; I'm surprised it took him so long.

B: That was obvious to everyone in my office; I'm surprised it took him so long.

[it/that $=$ that the company destroyed the file]

Likewise in (10), with the factive adjectival predicate be aware. In (11), that and it are equally felicitous in effecting immediate pronominal reference to a property when the property is mentioned within a factive complement.

(10) a. Alex is aware that the company destroyed the file. But it took him by surprise.

b. Alex is aware that the company destroyed the file. But that took him by surprise.

(11) a. Alex verified that this candidate is fluent in Berber. It's an important qualification for the position.

b. Alex verified that this candidate is fluent in Berber. That's an important qualification for the position.

The presupposed status of the content of the factive complement has the effect that this content is in-focus once the factive complement has been uttered.

Abstract entities mentioned within interrogative complements exhibit the same pattern of subsequent referential accessibility, as shown in (12)-(15).

(12) A: Alex wonders whether the company destroyed the file.

B: It's not likely. The file contained no incriminating information.

B: That's not likely. The file contained no incriminating information. [it/that $=$ that the company destroyed the file $]$

(13) a. Alex wonders whether the candidate is fluent in Berber, for it's the most important qualification for this position.

b. Alex wonders whether the candidate is fluent in Berber, for that's the most important qualification for this position.

[it/that $=$ being fluent in Berber]

(14) a. Alex wonders who destroyed the file; it has impeded the investigation.

b. Alex wonders who destroyed the file; that has impeded the investigation.

(15) a. Alex wonders which candidate is fluent in Berber. It is a very important qualification for this position. 
b. Alex wonders which candidate is fluent in Berber. That is a very important qualification for this position.

My consultants found the pronominal form it to be as felicitous as the demonstrative form that in (12)-(15); there was even a preference for it in (12) and (14).

\section{The referential accessibility of reasons and manners}

This section expands the inventory of abstract entities to be subject to the diagnostic of Borthen, Fretheim and Gundel (1997, 1999). The examples in (16)-(21) test for reference to reasons and manners introduced by adverbial constituents within clausal complements. In (16)-(17), with reasons and manners introduced in bridge verb complements, my consultants showed the, by now, familiar preference for that over it in subsequent reference to abstract entities introduced in these contexts.

(16) a. Alex thinks that Brenda addressed the protesters sympathetically, but firmly. It is the way that Susan would have handled the situation.

b. Alex thinks that Brenda addressed the protesters sympathetically, but firmly. That is the way that Susan would have handled the situation. [it/that = sympathetically, but firmly]

(17) a. Alex believes that the company hired Susan to create web pages. It is the purpose they specified in the job announcement.

b. Alex believes that the company hired Susan to create web pages. That is the purpose they specified in the job announcement. [it/that $=$ to create web pages]

In (18)-(19), this preference is neutralized, for reasons and manners introduced by adverbial expressions in factive complements.

(18) a. Alex regrets that Brenda addressed the protesters sympathetically. It is not the way he would have handled the situation.

b. Alex regrets that Brenda addressed the protesters sympathetically. That is not the way he would have handled the situation.

(19) a. Alex recognizes that the company hired Susan to create web pages. It is the purpose they specified in the job announcement.

b. Alex recognizes that the company hired Susan to create web pages. That is the purpose they specified in the job announcement.

In (20)-(21), the preference for that over it is likewise neutralized for reasons and manners introduced by adverbial expressions within interrogative complements. 


\section{Reference to Abstract Entities}

(20) a. Alex asked whether Brenda addressed the protesters sympathetically. It is not the way he would have handled the situation.

b. Alex asked whether Brenda addressed the protesters sympathetically. That is not the way he would have handled the situation.

(21) a. Alex wonders whether the company hired Susan to create web pages. It is the reason they specified in the job announcement.

b. Alex wonders whether the company hired Susan to create web pages. That is the reason they specified in the job announcement.

Reasons and manners thus pattern with other abstract entities in their referential behavior.

\section{Discussion of results}

\subsection{Implications for the semantic representation of factive and interrogative complements}

In sections 2 and 3, it was found that abstract entities mentioned within factive complements are accessible to immediate subsequent pronominal reference. This result must be generalized a bit. Cattell (1978) and subsequent researchers have noted that when clausal complement taking verbs and adjectives are classified according to whether they allow adjunct $w h$-extraction out of their complements, there are some verbs and adjectives which are not factive (in the Kiparsky and Kiparsky 1971 sense of presupposing the truth of their complement clauses), but which pattern with the factives. These include verbs such as agree, emphasize, doubt, and deny, and the adjectival predicate be certain. These pattern with factives according to the present criterion as well, as in (22).

(22) a. Alex and Susan agree that the company destroyed the file. I'm surprised that they believe it.

b. Alex and Susan agree that the company destroyed the file. I'm surprised that they believe that.

Although these verbs and adjectives do not carry a presupposition of the truth of their complements, they do seem to require that their complements denote established discourse entities, a property which they share with the factives. This property seems to be the key to the referential behavior observed here. There isn't a convenient way to designate these non-factive verbs and adjectives that pattern with the factives. (On Cattell's classification, they are non-volunteer stance, and include some response stance predicates and some non-stance predicates.) I will call these, together with factives, the established content (EC) verbs and adjectives. 
These considerations, taken together, motivate a semantic representation of EC ascriptions on which the content of the complement clause restricts a discourse entity, a fact or associated situation or event. In Discourse Representation Theory, for example, the factive ascription in (9A) must occur in a context such as that shown in (23), in which, on the formulation adopted here, an established or accommodated event in a Davidsonian event semantics (such as that of Higginbotham 1985) is restricted by the EC complement to be one in which the company destroyed the file.

\begin{tabular}{|l|}
\hline$u, v, z, e$ \\
\hline Alex $(u)$ \\
Company $(v)$ \\
File $(z)$ \\
destroy $(v, z, e)\left(w_{o}\right)$ \\
verify $(u, \lambda w[$ destroy $(v, z, e)(w)])$ \\
\hline
\end{tabular}

Schulz (1999) presents and discusses a similar proposal expressed within Heim's (1982) File Card semantics.

For our purposes here, the discourse status of the associated event will be expressed by the iota operator, as in (24), restricted by the content of the complement clause.

$$
\mathfrak{l} e\left[\operatorname{destroy}(c, f, e)\left(w_{o}\right)\right][\operatorname{verify}(a, \lambda w[\operatorname{destroy}(c, f, e)(w)])]
$$

The results obtained for interrogative complements in sections 2 and 3 above suggest that the content of an interrogative complement should, like that of factive and other EC complements, serve to restrict a discourse situation or event.

But this status has not been expressed in semantic representations of interrogative complements in the literature, such as the Karttunean (1977) representation of $(12 \mathrm{~A})$ as in $(25) .^{3}$

$$
\begin{gathered}
\text { wonder }\left(a, \lambda p\left[p\left(w_{o}\right) \&(p=\lambda w[\operatorname{destroy}(c, f, w)] \vee\right.\right. \\
p=\lambda w[\sim \operatorname{destroy}(c, f, w)])])
\end{gathered}
$$

On the representation in (25), Alex is in the relation wonder to those propositions holding of the actual world on which the company destroyed or didn't destroy the file in question. Which proposition it is that Alex is in the wonder relation to depends on which holds of the actual world. Since Alex doesn't know which such proposition holds of the actual world, it follows that Alex doesn't know which

\footnotetext{
${ }^{3}$ Karttunen's (1977) representation was based on earlier work by Hamblin (1973). The notational adaptation and simplification of Karttunen's proposal given in (25) is adopted here following Rullmann (1995).
} 


\section{Reference to Abstract Entities}

proposition he is in the wonder relation to. The Karttunen approach thus makes the proposition to which Alex is related by wonder opaque to Alex himself.

The results in (12)-(13) of section 2, regarding accessibility to pronominal reference, support a treatment of interrogative complements parallel to that given above for factive and other EC complements. We can represent (12A) as in (26), and the wonder-ascription in (14a) as in (27).

$$
\begin{aligned}
& \exists / \mathfrak{p}[p=\lambda w[\operatorname{destroy}(c, f, w)]]\left[\operatorname{wonder}\left(a, \lambda q\left[q=p\left(w_{o}\right)\right]\right)\right] \\
& \exists / \mathrm{P} P[P(w)=\lambda x[\operatorname{destroy}(x, f)(w)]]\left[\operatorname{wonder}\left(a, P\left(w_{o}\right)\right)\right]
\end{aligned}
$$

The representation in (26) is explicitly about the proposition that the company destroyed the file, construed as the set of possible worlds in which that happened, and it asserts that Alex is in the wonder relation to the proposition that the actual world is one of the worlds in that set. On this interpretation, the proposition that the company destroyed the file must be an established discourse entity prior to the utterance of (12A), or it must be accommodated in the sense of Heim (1982). Likewise, the representation in (27) pertains to the property that holds (across worlds) of those who destroyed the file, and asserts of it that Alex is in the relation of wonder to this property instantiated on the actual world. The property must be either discourse established prior to the utterance of $(14 \mathrm{a})$, or accommodated on the occasion of utterance. The possibility of accommodation must be observed here for examples like (28), adapted from Lahiri (1991),

Alex wonders where he can get gas around here.

which can be used in a context in which the content of the complement clause does not have an associated situation or event that was a prior discourse entity.

The representation of factive and interrogative complements developed in this section provides a foundation for an account, along the lines of that given by Szabolcsi and Zwarts (1992/93), of the weak islandhood of these complements to wh-extraction. Hegarty (1999) develops this connection.

\subsection{On the referential accessibility of abstract entities}

In this section, we'll consider further the nature of the abstract entities subject to the generalizations arrived at in previous sections. What are abstract entities, for the purpose of the present results? What properties characterize or distinguish abstract entities in a way that might determine their special behavior with regard to referential accessibility?

For events and situations, there are fairly extensive results in the literature, on which we might draw. Lasersohn (1990), discussing the semantics of plurals, proposes that events have the algebraic structure of a join semilattice. Likewise, Schein (1993), also discussing plurals, proposes a mereology of events with "part- 
of" structure, a partial ordering. Ginzburg (1995a, b) proposes that situations are structured as a Heyting algebra of states of affairs. Propositions, partially ordered under the relation of entailment, constitute a similar partial algebraic structure. Peterson (1997) cautions against reducing any of these abstract entities to the others, and urges that each be treated in its own right. Finally, Hegarty (1999) argues that reason expressions denote elements of a domain with the algebraic structure of a join semilattice; likewise for manner expressions. Thus, there is a fairly extensive literature in which abstract elements are analyzed as elements in algebraic systems with partial structure.

Recall now the results in (7) in section 1 above, which showed that abstract entities introduced by nominals share the referential accessibility of concrete entities. Abstract entities which are not discourse established are inaccessible to immediate pronominal reference only when they are introduced by non-nominal expressions. This might reflect facts about the processing of non-nominal expressions, to be captured in conditions on the cognitive status of their referents, or conditions on the ranking of forward looking centers, indexed explicitly to the linguistic form of non-nominal expressions.

Alternatively, we could approach the problem on the view argued by Fraurud (1996), that referential accessibility depends in part on the cognitive ontology of the referent. Fraurud identifies three different types of entity within a cognitive ontology: individuals, functionals, and instances of a kind or of a continuous substance. Fraurud argues that the cognitive type of an entity confers upon it a degree of individuation, different from that of entities of other cognitive types, which influences the entity's referential accessibility.

The relative referential inaccessibility of abstract entities, when they are referred to with non-nominal expressions, could reflect their ontological status, conferred by the mathematical structure of their denotation domains. Reference is dependent on an apparatus of individuation. If nominal expressions structure their referents as members of unordered sets, then abstract entities introduced by nominal expressions should be individuated on a par with concrete entities. Abstract entities introduced by non-nominal expressions would, in contrast, be individuated as elements of more structured algebraic systems, and thus, by conjecture, individuated to a lesser degree than independent individuals. This might equally well have significance for the cognitive status of the referent, or the ranking of the entity as a forward looking center of the utterance, but a significance that originates in the nature of the referent itself, and the algebraic system of which it is a part, rather than in the linguistic form used to introduce it.

\section{Conclusions}

This paper has argued the following: 
- that abstract entities introduced by non-nominal expressions are merely activated when introduced within bridge verb complements, but are rendered in-focus when introduced within factive (and other EC) complements, and within interrogative complements;

- that properties, reasons and manners pattern with propositions, facts, and situations in their referential accessibility behavior; and

- that referential accessibility facts in different complement types lead to explicit representations of the interpretations of factive (and other EC) ascriptions and of ascriptions with embedded interrogatives.

Furthermore, the results given here, and those of Borthen, Fretheim and Gundel, $(1997,1999)$ can aid the project of ranking the forward looking centers $\{\mathrm{Cf}\}$ of English according to how likely they are to be the backward looking center of the next utterance. The results given here, specifically, show that for abstract entities mentioned by non-nominal expressions within clausal complements, the semantic type of the complement clause is relevant. Furthermore, the structure of the expression's denotation domain seems to be relevant. These points support the proposal of Cote (1998) that Cf's must be ranked in part on semantic grounds, and not just on the basis of superficial syntax.

\section{References}

Ariel, Mira. 1990. Accessing NP Antecedents. London: Routledge.

Borthen, Kaja, Thorstein Fretheim and Jeanette. K. Gundel. 1997. What brings a higher-order entity into focus of attention? In R. Mitkov and B. Boguraev (eds.) Operational factors in practical, robust anaphora resolution, pp.88-93.

Borthen, Kaja, Thorstein Fretheim and Jeanette K. Gundel. 1999. Relevance and the role of context in pronominal reference to higher order entities: Evidence from English and Norwegian. Ms. NTNU, Trondheim.

Cattell, Ray. 1978. On the source of interrogative adverbs. Language 54: 61-77. Cote, Sharon. 1998. Ranking forward-looking centers. In M. A. Walker, A. K. Joshi, and E. F. Prince (eds.) Centering theory in discourse. Oxford: Oxford University Press, pp.55-69.

Fraurud, Kari. 1996. Cognitive ontology and NP form. In T. Fretheim and J. K. Gundel (eds.) Reference and referent accessibility, pp.65-87.

Ginzburg, Jonathan. 1995a. Resolving questions I. Linguistics and Philosophy 18: 459-527.

Ginzburg, Jonathan. 1995b. Resolving questions II. Linguistics and Philosophy 18: $567-609$. 
Grosz, Barbara J., Aravind K. Joshi, and Scott Weinstein. 1983. Providing a unified account of definite noun phrases in discourse. In Proceedings for the $21^{\text {st }}$ annual meeting of the Association for Computational Linguistics, pp.4450.

Grosz, Barbara J., Aravind K. Joshi, and Scott Weinstein. 1995. Towards a computational theory of discourse interpretation. Computational Linguistics 21:203-25.

Gundel, Jeanette K., Nancy Hedberg and Ron Zacharski. 1989. Givenness, implicature and demonstrative expressions in English discourse. Chicago Linguistics Society 25: 89-103.

Gundel, Jeanette K., Nancy Hedberg and Ron Zacharski. 1993. Cognitive status and the form of referring expressions in discourse. Language 69:274-307.

Hamblin, C. L. 1973. Questions in Montague English. Foundations of Language 10: 41-53.

Hegarty, Michael. 1999. The Algebraic Structure of Denotation Domains. Ms., University of Minnesota.

Heim, Irene. 1982. The Semantics of Definite and Indefinite Noun Phrases. Doctoral dissertation, University of Massachusetts, Amherst.

Higginbotham, James. 1985. On semantics. Linguistic Inquiry 16:547-593.

Karttunen, Laurie. 1977. Syntax and semantics of questions. Linguistics and Philosophy 1:3-44.

Kiparsky, Paul and Carol Kiparsky. 1971. Fact. In D. Steinberg and L. Jacobovits, (eds.) Semantics. Cambridge: Cambridge University Press, pp. 345-369.

Lahiri, Utpal. 1991. Embedded Interrogatives and Predicates that Embed Them.

Doctoral dissertation, MIT.

Lasersohn, Peter. 1990. A Semantics for Groups and Events. Garland.

Peterson, Philip L. 1997. Fact Proposition Event. Dordrecht: Kluwer.

Rullmann, Hotze. 1995. Maximality in the Semantics of Wh-Constructions. Doctoral dissertation, University of Massachusetts, Amherst.

Schein, Barry. 1993. Plurals and Events. Cambridge, MA: MIT Press.

Schulz, Petra. 1999. Getting the Facts: Finite Complements, Factive Verbs and their Acquisition. Doctoral dissertation, Tubingen University.

Szabolcsi, Anna and Frans Zwarts. 1992/93. Weak islands and an algebraic semantics for scope taking. Natural Language Semantics 1:235-284.

Webber, Bonnie Lynn. 1988. Discourse deixis and discourse processing. Technical report, University of Pennsylvania.

Michael Hegarty

Department of English, Allen Hall

Louisiana State University

Baton Rouge, LA 70803

MHEGAR1@LSU.EDU 